\title{
Acute Stent Migration into the Right Ventricle in a Patient with Iliac Vein Stenting
}

\author{
Torulv Holst ${ }^{1}$ Thorsten Großwendt ${ }^{1}$ Majd Makarious Laham ${ }^{1} \quad$ Mehdy Roosta-Azad ${ }^{1}$ Afsaneh Zandi ${ }^{1}$ \\ Markus Kamler ${ }^{1}$
}

${ }^{1}$ Heart Center Essen Huttrop, University Hospital Essen, Essen, Germany

Thorac Cardiovasc Surg Rep 2018;7:e7-e8.
Address for correspondence Torulv Holst, MD, Heart Center Essen Huttrop, University Hospital Essen, Herwarthstrasse 100, Essen 45138, Germany (e-mail: torulv.holst@heh.uk-essen.de).
Abstract
Keywords
- venous disease
- endovascular procedures/stents
- except PCI
- heart failure
- cardiopulmonary bypass
- $\mathrm{CPB}$

Endovascular stent placement for chronic postthrombotic iliofemoral venous obstructive lesions is an effective therapeutic option and might be complicated by stent migration. We report a case of a venous stent that was lost from the iliac vein into the right ventricle rescued by emergent open-heart surgery.

\section{Introduction}

Postthrombotic syndromes have been treated by endovascular stents with good results. ${ }^{1-3}$ Stent migration is a rare event especially into the right ventricle, where potentially serious complications including cardiac arrhythmias and heart failure may occur. To the best of our knowledge, only few cases with venous stent migration into the heart and fatal ending are reported so far and no case with open-heart surgery. ${ }^{4,5}$

We present a case of stent migration into the right ventricle after stent placement into the iliac vein.

\section{Case Description}

A 49-year-old female patient, who suffered from an iliofemoral deep vein thrombosis (DVT) due to the presence of chronic obstruction of the iliac vein system, underwent venous stenting using a venous stent for recanalization (Boston Scientific, EPIC Stent, size $12 \mathrm{~mm} / 40 \mathrm{~mm}$ ). One hour postprocedural echocardiography and computed tomography scan (- Fig. 1) revealed stent migration into the subvalvular chordal structures of the right ventricle causing significant tricuspid regurgitation. The patient became hemodynamically unstable due to severe cardiac arrhythmias with heart rates up to 180 per minute and was scheduled for emergency surgery.

Median sternotomy and bicaval cannulation for cardiopulmonary bypass was performed. Transesophageal echocardiography showed further migration of the stent toward the right ventricular outflow tract. To prevent further migration into the pulmonary vasculature, manual compression was applied. The right atrium was opened in beating heart technique to locate the stent.

Despite the fact, that the stent was entrapped by subvalvular chordal structures of the tricuspid valve due to the stent design with wire brackets, it was possible to recover it without harming the tricuspid valve and adjacent structures (-Fig. 2). The postoperative course was uneventful and the patient was discharged on postoperative day 7. Postoperatively, the patient received warfarin. No reocclusion of the iliac vein occurred and the patient underwent no redo stenting. The patient is in a good condition 1 year after the procedure.

\section{Discussion}

Interventional stenting for chronic obstruction of the iliac vein system represents a relatively new therapeutic option, received

November 21, 2017 accepted after revision January 2, 2018
DOI https://doi.org/ 10.1055/s-0038-1629898. ISSN 2194-7635.
๑) 2018 Georg Thieme Verlag KG
Stuttgart · New York

License terms

(1) $\Theta \circledast$ 


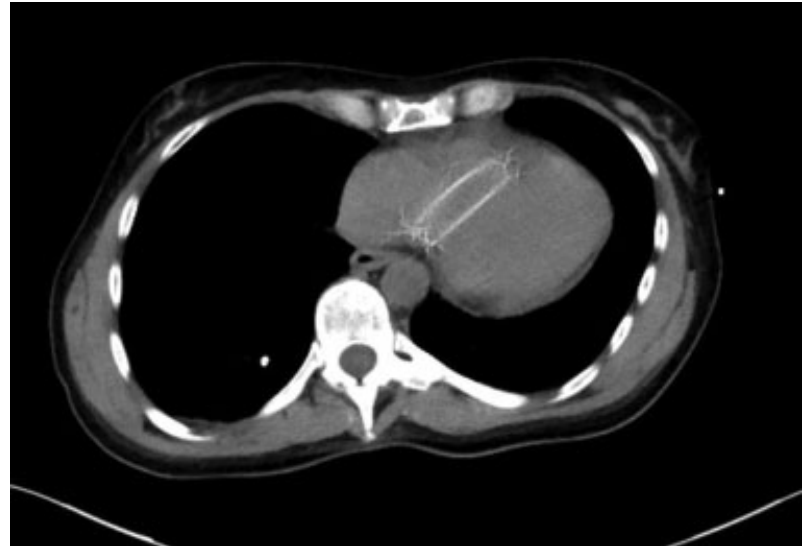

Fig. 1 Chest computer tomography with the venous stent dangling in the tricuspid valve apparatus.

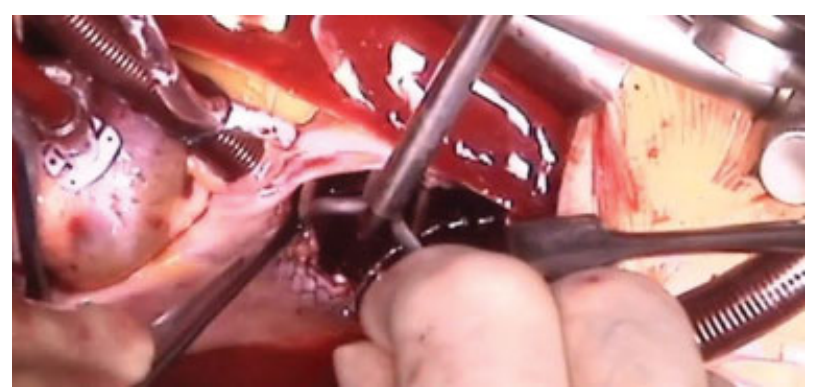

Fig. 2 Intraoperative finding: Removal of the stent from the tricuspid valve apparatus.

which became feasible and safe after development of new flexible stent designs with high radial forces. ${ }^{1}$ Therefore, only a few exceptional cases of stent migration after iliofemoral vein stenting have been reported. ${ }^{4,5}$ More frequently, cases of venous stent migration have been reported for the nutcracker syndrome whereby a smaller stent is placed in the left renal vein. ${ }^{6}$ One case of a 55 -year-old woman ended fatally after transvenous migration of an infrarenal inferior vena cava stent into the right atrium and through the intraatrial septum due to ventricular fibrillation. ${ }^{4}$

As our patient was symptomatic and unstable with significant cardiac arrhythmias, our multidisciplinary heart team decided that time-consuming attempts to percutaneously remove the stent was not an appropriate option in this case as described elsewhere. ${ }^{5}$ Due to the rapid migration of the stent into the right atrium and subsequent dislocation into the right ventricle, an emergent surgery was planned.

Surgery was performed without inducing cardiac arrest to reduce surgical trauma and to avoid myocardial ischemia. Overall, patient's postoperative course was uneventful. The integrity and functionality of the tricuspid valve and its subvalvular apparatus was completely preserved with this technique.

As stent migration represents a rare, however, potentially serious life-threatening complication of iliofemoral vein stenting, a multidisciplinary rescue plan should be launched. Compared with interventional strategies, emergent openheart surgery might be safer and a less harmful strategy to rescue the stent due to a significantly lower risk of damaging the tricuspid valve and its subvalvular structures. The precise location of the stent that can be obtained using computed tomography and transesophageal echocardiography is essential when angiography reveals the absence of the stent in the iliac vein system.

\section{References}

1 Lichtenberg MK, Jalaie $\mathrm{H}$. Recanalization techniques for venous outflow obstruction [in German]. Dtsch Med Wochenschr 2016; 141(24):1736-1739

2 Falcoz MT, Falvo N, Aho-Glélé S, et al; Burgundy Research; Study Group on Treatment of Venous Diseases. Endovascular stent placement for chronic post-thrombotic symptomatic ilio-femoral venous obstructive lesions: a single-center study of safety, efficacy and quality-of-life improvement. Quant Imaging Med Surg 2016;6(04):342-352

3 Srinivas BC, Patra S, Reddy B, Nagesh CM, Agarwal N, Manjunath $\mathrm{CN}$. Outcome of venous stenting following catheter directed thrombolysis for acute proximal lower limb venous thrombosis: a prospective study with venous Doppler follow-up at 1-year. Cardiovasc Interv Ther 2015;30(04):320-326

4 Steinberg E, Gentile C, Heller M, Kaban N, Bang E, Li T. Intracardiac venous stent migration: emergency department presentation of a catastrophic complication. J Emerg Med 2017;53(01):e11-e13

5 Ashar RM, Huettl EA, Halligan R. Percutaneous retrieval of a Wallstent from the pulmonary artery following stent migration from the iliac vein. J Interv Cardiol 2002;15(02):101-106

$6 \mathrm{Wu}$ Z, Zheng X, He Y, et al. Stent migration after endovascular stenting in patients with nutcracker syndrome. J Vasc Surg Venous Lymphat Disord 2016;4(02):193-199 